\title{
Estimating spatial distribution of American lobster Homarus americanus using habitat variables
}

\author{
Jui-Han Chang ${ }^{1, *}$, Yong Chen ${ }^{1}$, Daniel Holland ${ }^{2}$, Jonathan Grabowski ${ }^{2}$ \\ ${ }^{1}$ School of Marine Sciences, University of Maine, Orono, Maine 04469, USA \\ ${ }^{2}$ Gulf of Maine Research Institute, 350 Commercial Street, Portland, Maine 04101, USA
}

\begin{abstract}
The spatial distribution of the American lobster Homarus americanus is influenced by many factors, which are often difficult to quantify. We implemented a modeling approach for quantifying season-, size-, and sex-specific lobster spatial distribution in the Gulf of Maine with respect to environmental and spatial variables including bottom temperature, bottom salinity, latitude, longitude, depth, distance offshore, and 2 substratum features. Lobster distribution was strongly associated with temperature and depth, and differed seasonally by sex. In offshore waters in the fall, females were dominant at higher latitudes and males at lower latitudes. This segregation was not apparent in the spring although females were still dominant at higher latitudes in offshore waters. Juveniles and adults were also distributed differently; juveniles were more abundant at the lower latitudes in inshore waters, while adults were more widespread along the entire coast. These patterns are consistent with the ecology of the American lobster. This study provides a tool to evaluate changes in lobster spatial distribution with respect to changes in key habitat and other environmental variables, and consequently could be of value for the management of the American lobster.
\end{abstract}

KEY WORDS: American lobster - Homarus americanus - Spatial distribution · Gulf of Maine 2-stage GAM

Resale or republication not permitted without written consent of the publisher

\section{INTRODUCTION}

The American lobster, Homarus americanus, is distributed throughout the continental shelf of the Northwest Atlantic from Newfoundland, Canada to offshore North Carolina, USA (Lawton \& Lavalli 1995). Although lobster are mainly found in waters shallower than $50 \mathrm{~m}$ (Pringle \& Burke 1993), they also inhabit waters up to $700 \mathrm{~m}$ deep (Cooper \& Uzmann 1971). $H$. americanus is the most abundant large mobile benthic invertebrate in the region (Steneck \& Wilson 2001) and supports one of the most valuable commercial fisheries in the US, with landings of over $45000 \mathrm{t}$ worth over \$386 million in 2006 (http://www.st.nmfs. noaa.gov/st1/commercial/landings/annual_landings. html). The majority of commercial catch in the US is from inshore waters of the Gulf of Maine (GOM; ASMFC 2009).

Although lobster density varies considerably along the coast in the GOM (Steneck \& Wilson 2001), tempo- ral patterns are similar geographically (Steneck \& Wilson 2001, Incze et al. 2006). Temporal consistency in the distribution of lobster at large spatial scales suggests that the distribution of lobster may be regulated by environmental variables. Furthermore, recent findings on the dispersal potential of lobsters in the GOM suggest that a significant amount of lobster recruitment is derived from local sources (Xue et al. 2008, Incze et al. 2010), which implies that local habitat features and fine-scale oceanic processes also influence the spatial distribution of lobster in the GOM.

The spatial distribution of the American lobster varies seasonally. In the GOM, lobsters migrate into inshore waters in the spring and then into deep waters in late fall (Chen et al. 2006). In Great Bay, New Hampshire (Watson et al. 1999) and in Canadian estuaries (Munro \& Therriault 1983), most movement is into estuaries during the spring and towards the coast for the rest of the year, suggesting control by environmental variables such as temperature and salinity. 
Spatial distribution of lobster can also differ greatly by sex and size (Karnofsky et al. 1989, Campbell 1990). Small lobsters are more likely to reside in inshore waters, whereas large lobsters are more common in offshore waters (Cooper et al. 1975, Briggs 1985). These differences in spatial distribution are likely due to sex- and size-specific responses of lobster to the environment (Jury et al. 1994, Factor 1995). Although season-, size-, and sex-specific patterns in the spatial distribution of the American lobster are prevalent, these have yet to be modeled quantitatively based on habitat and environmental variables. Such models may be useful in characterizing climate-induced range contraction and in defining appropriate management actions.

Statistical regression models have been widely used for quantifying and predicting habitat use of fish species as a function of environmental variables (Eastwood et al. 2001, Kupschus 2003, Jensen et al. 2005, Austin 2007). These analyses can be used to evaluate spatial variability of biological production along environmental gradients, to manage populations that will be impacted by habitat alterations due to coastal development and climate change, and to designate and protect essential fish habitat (Austin 2007).

The general additive model (GAM; Hastie \& Tibshirani 1990) is the most general form of regression models (Guisan et al. 2002). GAMs are more suitable for ecological studies than other types of regression model because of their flexibility and capacity to explore species responses to environmental gradients both linearly and nonlinearly (Lehmann et al. 2002, Ray et al. 2002). An extension of GAMs in spatial modeling is the 2-stage GAM in which presence/absence data and density of presence observations are used sequentially in deriving density estimates (Barry \& Welsh 2002, Jensen et al. 2005). The coupled model has advantages in preserving the information of zero observations, which are common in fisheries (Maunder \& Punt 2004).

In this study, we develop season-, size-, and sexspecific models that predict the spatial distribution of American lobster along the coast of the GOM by quantifying lobster responses to environmental conditions using a 2-stage GAM approach. We then validate the performance of the 2-stage GAMs and evaluate whether lobster responses differ by season, sex and size.

The Gulf of Maine Ocean Observing System (GoMOOS) circulation nowcast/forecast system is an operational numerical prediction system for the GOM (Xue et al. 2005). The model produces daily and shortterm forecasts of physical properties such as temperature and salinity in 3 dimensions. Using the data produced by this system and the habitat models developed in this study, we can predict the spatial distribution of lobsters in the GOM. We used the 2006
GoMOOS circulation nowcast/forecast system physical output to predict season-, size- and sex-specific spatial distribution. Variation in spatial distribution of the American lobster by season, sex and size is evaluated and potential ecological and management implications are discussed.

\section{MATERIALS AND METHODS}

Maine-New Hampshire Inshore Trawl Survey data. The Maine-New Hampshire Inshore Trawl Survey is a biannual fishery-independent survey operated by the Maine Department of Marine Resources (DMR) each fall and spring since fall of 2000. Fig. 1 shows data from surveys carried out in spring and fall in 2006. The survey follows a stratified random design with 4 depth strata (9-37 m, 37-64 m, 64-100 m, and >100 m with $12 \mathrm{~km}$ offshore limit) and 5 longitudinal regions based on oceanographic, geological, and biological characteristics. The survey total area is $16002 \mathrm{~km}^{2}$ and targets 115 stations (137 $\mathrm{km}^{2}$ per station) per season. The trawl is designed in such a way as to effectively sample complex bottom in the nearshore areas of the GOM without targeting any specific near-bottom species (Chen et al. 2006). Target tow duration is $20 \mathrm{~min}$ at 2.5 knots to cover a mean distance of $1509 \mathrm{~m}$ with an

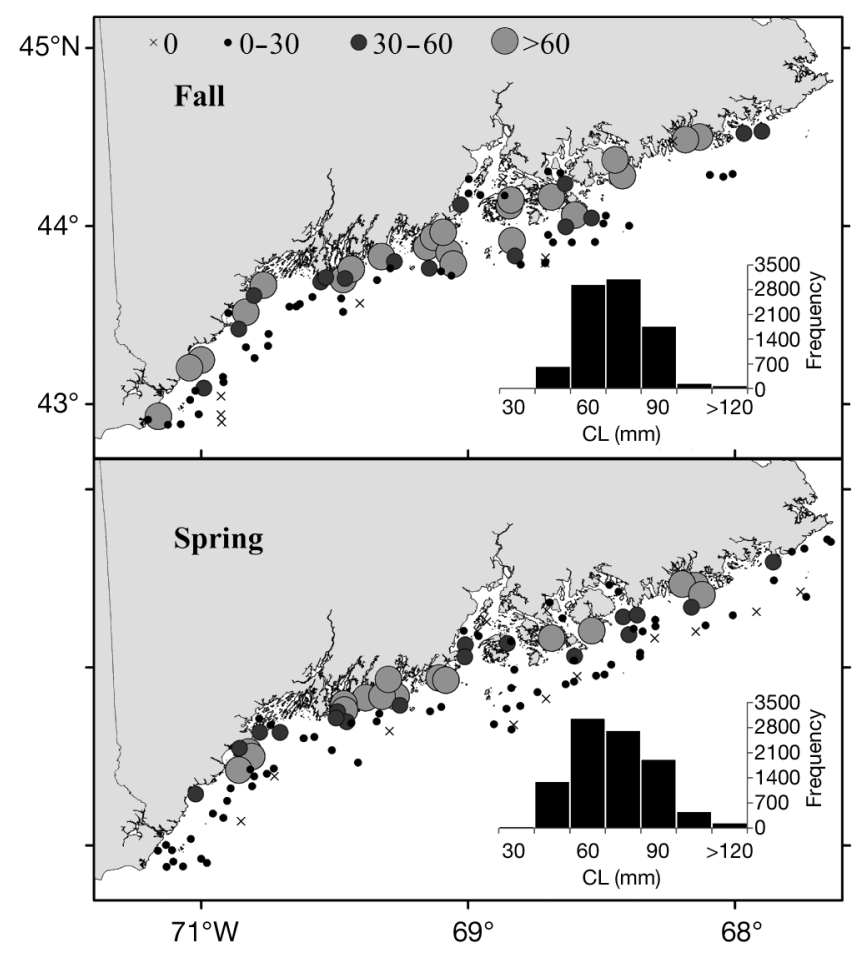

Fig. 1. Homarus americanus. The density (per tow record) and size frequency for spring and fall surveys in 2006. CL = carapace length 
average swept area of $\sim 15853 \mathrm{~m}^{2}$ per tow. All the lobsters captured are counted and sex, carapace length (CL), weight, and presence of eggs, v-notches, and damage is measured. In addition to recording the start/end times and coordinates of each tow, a Sea-Bird ElectronicsTM 19plus SEACAT profiler is attached to the net to collect start/end depth, bottom salinity, and bottom temperature. In this study, a total of 1712 tow records that sampled 96596 lobsters between fall 2000 and fall 2007 were used. The size of individual lobsters ranged between 19 and $186 \mathrm{~mm}$ and between 16 and $201 \mathrm{~mm} \mathrm{CL}$ for the spring and fall surveys, respectively.

Spatial and environmental variables. Our GAM models explored the influence of bottom temperature, bottom salinity, 2 sediment-related and 4 spatial variables (latitude, longitude, depth and distance offshore) on the distribution of the American lobster. These variables were selected because they are known to influence the distribution of American lobster. For instance, water temperature has a strong effect on survival rate, reproduction, growth and maturation (Aiken \& Waddy 1986). Fluctuations of salinity can induce physiological changes that may be extremely stressful to lobster (Jury et al. 1994). Wahle \& Steneck (1991) suggested that local lobster density might be correlated with shelter availability. D. Lincoln \& K. L. Lavalli (unpubl.) overlaid the 2 lobster spatial distribution maps published by Grosslein \& Azarovitz (1982) for Nova Scotia to Cape Hatteras and Backus (1987) for Georges Bank on substrate maps and found lobsters more frequently on the edges between 2 different substrates. Lobster density and size composition also vary with water depth (Wahle \& Steneck 1991, Wilson 1998, Palma et al. 1999, Chen et al. 2006) and distance offshore, due to seasonal movements (Munro \& Therriault 1983, Watson et al. 1999).

Temperature and salinity were obtained directly from the survey. Sediment-related variables were obtained from the map of sediment grain-size distribution for the continental margin of the eastern US (resolution: 0.00001 decimal degrees; $1.11 \mathrm{~m}$ ). Sediment types include bedrock, gravel, gravel-sand, sand, clay-silt/sand, sandclay/silt, clay, sand-silt/clay, and sand/silt/clay (Poppe et al. 2005). The sediment type and the shortest distance from a sampling station to a boundary between different sediments (distance to sediment boundary) were assigned to each sampling station using ArcGIS 9.3. Distance offshore was calculated using ArcGIS as the shortest distance to the mainland.

Model development. Standardized lobster densities (per min towing; $792 \mathrm{~m}^{-2}$ ) were divided by sex and 2 size classes, juveniles ( $\leq 60 \mathrm{~mm} \mathrm{CL}$ ) and adults (>60 mm CL) (minimum size at maturity for GOM stock; ASMFC 2009). Seasonal movement starts to change as individuals become functionally mature (Factor 1995). To depict such behavioral differences, we used minimum size at maturity to distinguish juvenile and adult. The spring and fall survey data were analyzed separately. This approach resulted in 8 groups ( 2 size classes $\times 2$ sexes $\times 2$ seasons) that were modeled independently. The 2007 survey data, the most recent available, were excluded in the model development because they were used to validate model performance.

We used a 2-stage GAM (Barry \& Welsh 2002, Jensen et al. 2005). GAM1 uses a logic link function with a binomial error distribution to estimate the probability of presence of lobsters $(p)$, and GAM2 uses an identity link function with a Gaussian error distribution to estimate the log-transformed lobster density $(y)$. The comprehensive log-transformed lobster density $(D)$ was then estimated by multiplying the results generated from GAM1 and GAM2:

$$
\begin{aligned}
\operatorname{GAM} 1: \operatorname{logit}(p)= & \mathrm{s}(S)+\mathrm{s}(T)+\mathrm{s}(D e)+\mathrm{s}(D O)+\mathrm{s}(D S) \\
& +\mathrm{s}(L a)+\mathrm{s}(L o)+S e+\varepsilon \\
\text { GAM2: } \ln (y)= & \mathrm{s}(S)+\mathrm{s}(T)+\mathrm{s}(D e)+\mathrm{s}(D O)+\mathrm{s}(D S) \\
& +\mathrm{s}(L a)+\mathrm{s}(L o)+S e+\varepsilon \\
& \ln (D)=\mathrm{p} \ln (y)
\end{aligned}
$$

where $S$ : salinity; $T$ : temperature $\left({ }^{\circ} \mathrm{C}\right) ;$ De: depth (meter); DO: distance offshore $(\mathrm{km}) ; D S$ : distance to sediment boundary (km); La: latitude (degree); Lo: longitude (degree); Se: sediment type (categorical variable); and s: spline smoother.

The GAMs were estimated using the R 2.9.0 mgcv package with a penalized regression method in which degrees of freedom for each term was estimated in the model based on the tradeoff between model fitting and model smoothness. Chi-square and $F$ tests were performed for the statistical significance of each term in both GAM1 and GAM2, and only the significant terms $(p<0.05)$ were retained in the model. A preliminary analysis was conducted to evaluate the performance of variables in both single and interaction terms. This process starts by evaluating one variable and its interactions with all other variables, and then selecting the most significant interaction term. The selected interaction term was then included in the model with all other variables as main effects. We compared the performance of this model with the model containing all the variables but without any interaction terms. The interaction term was retained in the final model only if it was significant and increased the explanatory power of the model by at least $5 \%$ relative to the model without interaction terms.

Model validation. The estimated GAMs were used to predict lobster density for each station sampled in 
2007 (the data withheld in the estimation of the GAMs). The predicted densities $\left(D^{\prime}\right)$ were then regressed against the observed densities $(D)$ using the following simple linear regression model:

$$
\ln (D)=a+b \ln \left(D^{\prime}\right)
$$

The coefficient a indicates systematic bias in predicted densities. A value of coefficient $b$ not significantly different from 1 indicates that observed and predicted densities have similar spatial patterns. A 2-tail $t$-test was performed to test the hypotheses $H_{0}$ : $a=0$ and $H_{0}: b=1$ respectively for each modeling group. The overall relationship between the predicted and observed densities was also evaluated using adjusted $\mathrm{R}^{2}$.

To evaluate whether season, size, and sex influence lobster responses to their environment, we used the models developed for different season, sex, and size to predict lobster densities of other season, sex, and size class. For example, the models developed based on the spring-juvenile-male, fall-juvenile-female, and spring-adult-female data were used to predict the spring-juvenile-female data. The model-data mismatch impacts (MDMI) of sex, season, and size on the prediction of lobster densities were quantified using the following formula:

$$
\mathrm{MDMI}=\frac{R_{m}^{2}-R^{2}}{R^{2}}
$$

where $R_{m}^{2}$ is the sample size adjusted coefficient of determination using predictions from the mismatch model, and $R^{2}$ is the adjusted coefficient of determination using predictions from the model developed based on the correct sex, season, and size. A negative MDMI indicated that the model-data mismatch model predicted lobster density less effectively than the correct model.

Model prediction and mapping. To predict season-, size-, and sex-specific lobster distributions along the coastal waters of the GOM, a set of environmental and spatial variables that cover the whole study area were collected and added to the 8 modeling groups of GAMs. Monthly averages of point estimates of bottom temperature and bottom salinity in 2006 were obtained from the GoMOOS circulation nowcast/forecast system (Xue et al. 2005). The monthly data of April to June and October to December for each location were averaged to represent the temperature and salinity in spring and fall, respectively. Ordinary Kriging (ArcGIS) was applied to spatial interpolation of the seasonal temperature and salinity using the Gaussian semivariogram model to create continuous raster maps. A cell size of $15850 \mathrm{~m}^{2}$, which is the size of the swept area per tow, was chosen for the 2 raster maps to ensure a consistent spatial scale between lobster and environmental data. Depth was obtained from a GOM bathymetric raster map, which was derived from the United States Geological Survey, Coastal and Marine Geology Program (Roworth \& Signell 1998). The 3 layers were overlaid, and variables, including distance offshore, distance to sediment boundary and sediment type, were assigned to each cell. Lobster densities were estimated where environmental and spatial conditions were within the predictable ranges. Finally, we calculated ratios of female density to total density and adult density to total density for each cell in spring and fall, respectively to delineate differences in spatial distributions between the sexes and size classes in each season.

\section{RESULTS}

\section{Model performance}

The deviance of probability of presence and density of lobster explained by the various GAM1s and GAM2s varied from $53 \%$ to $72 \%$ for the 8 modeling groups except the spring-adult-female GAM1, which only explained $34 \%$ of the deviance (Table 1 ). All the predictor variables were significant and included in at least 4 of the final models. The significant predictor variables varied among different modeling groups for all GAM1s and GAM2s for the spring. In contrast, all the GAM2s for the fall included temperature, depth, distance offshore, and the latitude-longitude interaction term. Response curves for the predictor variables were similar, while differences were still detected among different modeling groups. We included a partial set of response graphs for the purposes of illustration and comparison (Figs. 2 to 4 ).

\section{Environmental variables}

Temperature was the most commonly included environmental variable in both GAM1s and GAM2s (Table 1). Probability of presence and density of lobster increased with temperature in all the models (Fig. 2).

Both probability of presence and density of lobster declined slightly with an increase of salinity over 31 . Seasonal differences in the response of lobster to low salinity (below 31) were detected by GAM1s, for which the predicted probability of presence was higher in the spring than in the fall (Fig. 2).

Effects of distance to sediment boundary were not significant in any of the GAM2s (Table 1). However, probability of presence of lobster (GAM1) decreased linearly with an increase of the distance. Effects of the distance on the probability of presence were more significant for juveniles than adults (Fig. 2). 


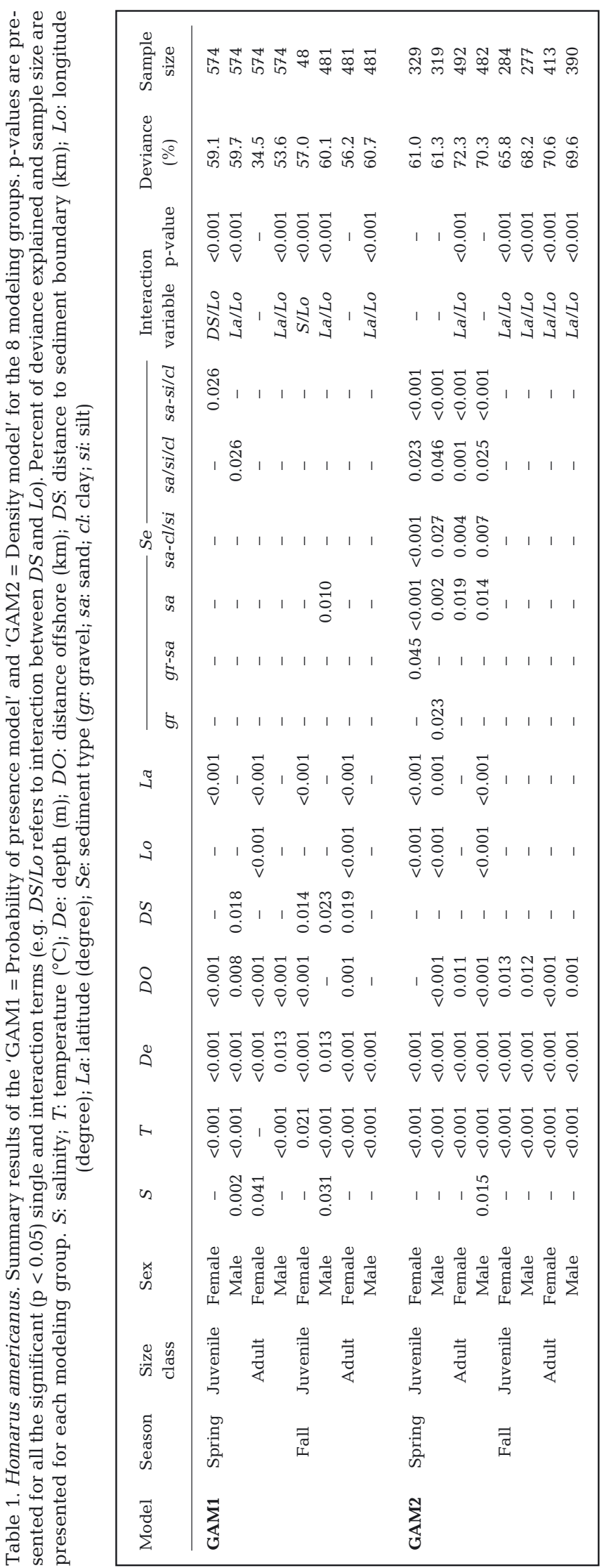

Effects of sediment type on the probability of presence were only significant for juveniles (Table 1). The probability of presence of juveniles was significantly lower in the sand, sand/silt/clay, and sand-silt/clay substrates compared with other sediment types. Sediment type only significantly affected lobster density in the spring. Highest lobster densities in spring were in the clay-silt/sand substrate for juveniles and in claysilt/sand and gravel-sand substrates for adults (Fig. 3).

\section{Spatial variables}

Depth had significant non-linear effects in GAM1s and GAM2s for all modeling groups (Table 1). The probability of presence peaked at depths ranging between 50 and $75 \mathrm{~m}$. Density was high at depths ranging from 30 to $70 \mathrm{~m}$, and decreased with increasing depth from 70 to $100 \mathrm{~m}$. Beyond $100 \mathrm{~m}$, few lobsters were caught in the survey, resulting in wide confidence intervals and variation in response curves (Fig. 4).

Effects of distance offshore were significant in most models (Table 1). The probability of lobster presence declined for distances ranging from 0 to $15 \mathrm{~km}$. Lobster density decreased linearly with distance offshore in the spring. In the fall, density decreased and then leveled off for juveniles beyond the distance of $7.5 \mathrm{~km}$; however, adults increased slightly beyond $20 \mathrm{~km}$. In general, few lobsters were caught in the survey beyond 15 and $20 \mathrm{~km}$ offshore, and response curves varied widely (Fig. 4).

Effects of longitude and latitude were significant either separately or accompanied in GAM1s and GAM2s for all modeling groups (Table 1), which suggested that lobster distribution may also be influenced by other environmental factors that were not included in this study (e.g. food availability).

\section{Model validation}

The eight 2-stage GAMs explained an average of $66 \%$ of the variation in lobster density from the 2007 trawl survey (Table 2). The lobster density models had adjusted $\mathrm{R}^{2}$ values ranging from 0.76 to 0.81 for fall and from 0.47 to 0.60 for spring. The spring-juvenile density had the poorest fit among all modeling groups. The intercepts (coefficient $a$ in Eq. 4) for the 8 modeling groups were all positive and significantly different from 0 except for fall-juvenile models. The slope coefficients ( $b$ in Eq. 4) were not significantly different from 1 for all the adult lobster models, whereas all the juvenile lobster models had slopes significantly larger than 1. These results suggest that the GAMs predicted lobster density relatively well, but with a slight bias 

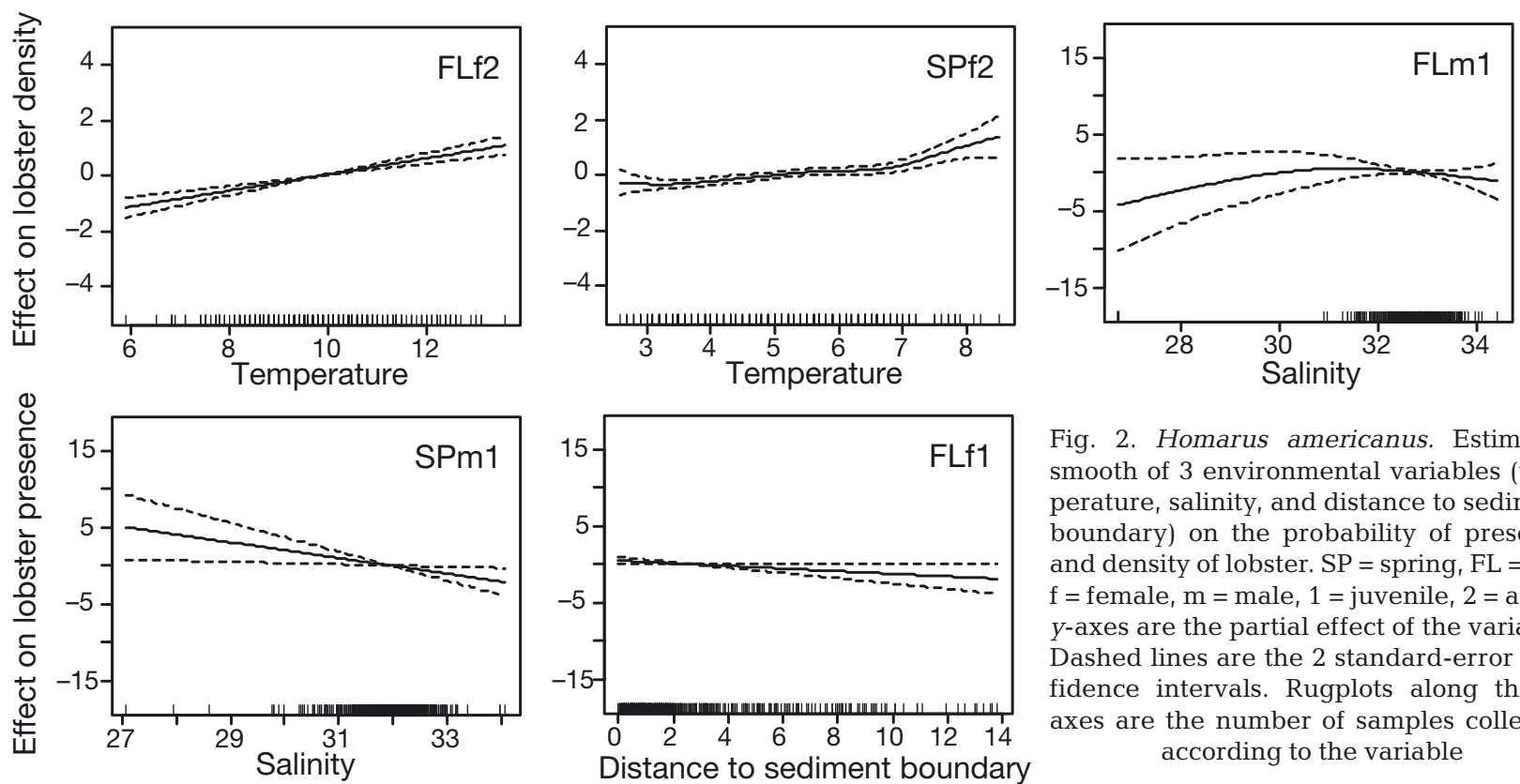

Fig. 2. Homarus americanus. Estimated smooth of 3 environmental variables (temperature, salinity, and distance to sediment boundary) on the probability of presence and density of lobster. SP = spring, FL = fall, $\mathrm{f}=$ female, $\mathrm{m}=$ male, 1 = juvenile, 2 = adult. $y$-axes are the partial effect of the variable. Dashed lines are the 2 standard-error confidence intervals. Rugplots along the $x$ axes are the number of samples collected according to the variable

toward underprediction for all groups. The degree of underprediction increased with density for juveniles but not for adults, suggesting that predicted density was more accurate for adults than for juveniles.

Validation analysis of MDMI (Fig. 5) suggested that the standardized deviation of $\mathrm{R}^{2}$ values decreased the most when model and data were mismatched by the seasons for each modeling group. Sex generally had the least influence among the 3 factors (i.e. season, sex, and size class); however, all the male groups had a lower $\mathrm{R}^{2}$ when predicted using the female models.

\section{Model prediction}

The season-, size-, and sex-specific spatial distributions of American lobster were estimated for 2006 (Fig. 6). In general, lobster density was predicted to be higher in inshore waters. The models predicted seasonal differences in lobster distribution by sex (Fig. 7). In offshore waters, significant sexual segregation occurred in the fall with females dominating the higher latitudes and males more abundant at lower latitudes. This segregation was not apparent in the spring, although females still dominated in offshore waters at higher latitudes. Males were predicted to be more abundant along the coast in the fall, and females in the spring. Although predicted lobster densities were low in Penobscot Bay, a difference in sex ratio was predicted in the estuary. Relatively more females remained in the bay in fall, whereas more males did so in the spring.

The models suggested that juveniles and adults are distributed differently. Juveniles were predicted to be more abundant in the inshore waters at lower latitudes (around Muscongus Bay and Casco Bay), while adults were more widespread along the entire coast (Fig. 7).
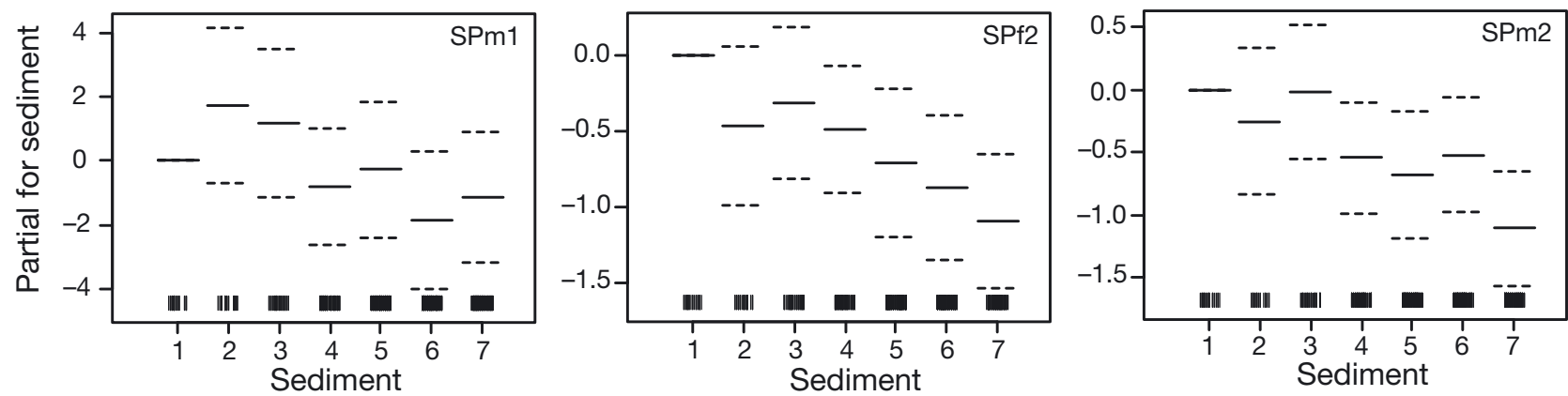

Fig. 3. Homarus americanus. Partial effect of sediment type on the probability of presence of male juveniles and density of adults in the spring. Sediment types: $1=\mathrm{cl}$-st/sd, $2=\mathrm{gr}, 3=\mathrm{gr}-\mathrm{sd}, 4=\mathrm{sd}, 5=\mathrm{sd}-\mathrm{cl} / \mathrm{st}, 6=\mathrm{sd} / \mathrm{st} / \mathrm{cl}, 7=\mathrm{sd}-\mathrm{st} / \mathrm{cl}$. See Fig. 2 and Table 1 for further explanation 

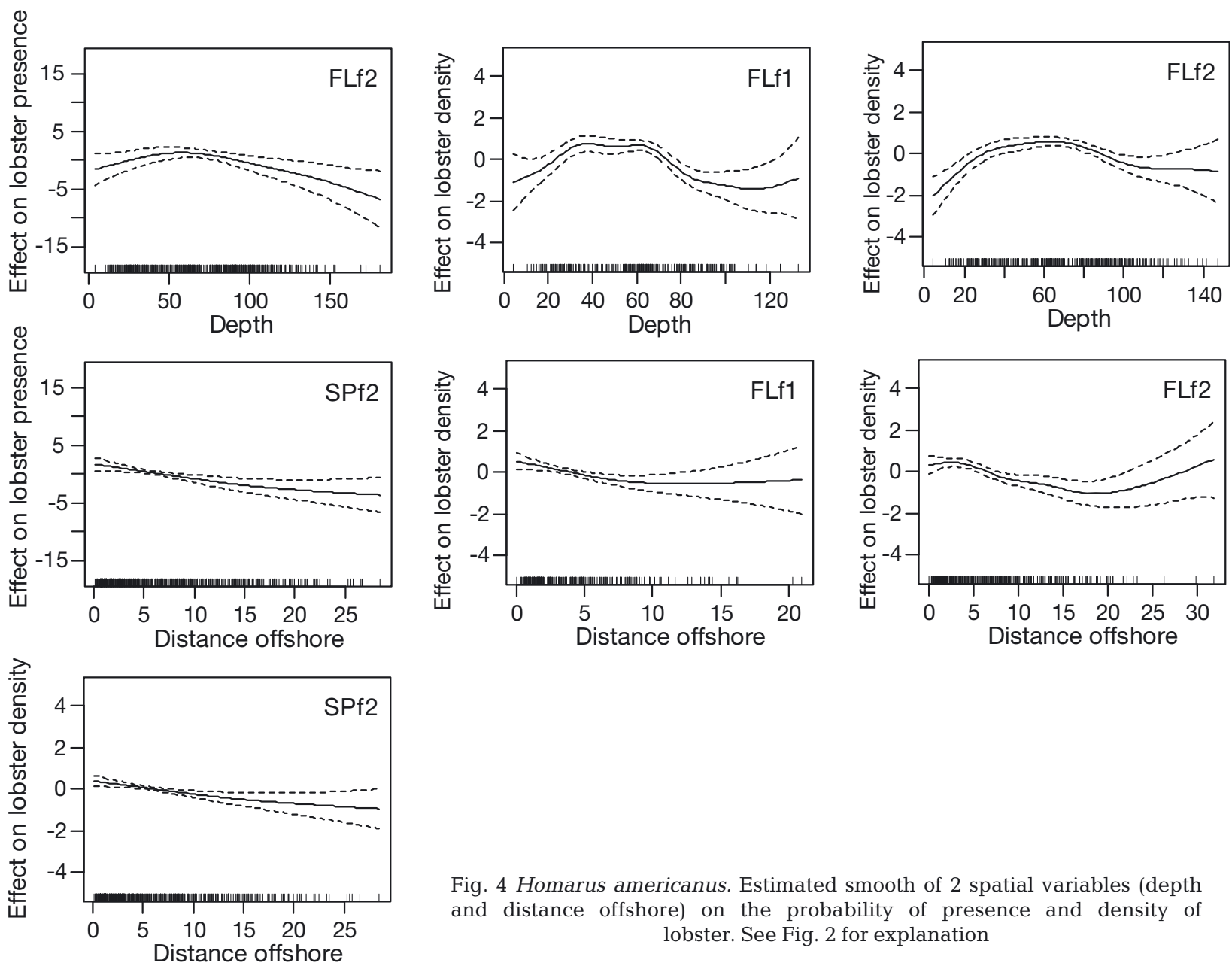

Fig. 4 Homarus americanus. Estimated smooth of 2 spatial variables (depth and distance offshore) on the probability of presence and density of lobster. See Fig. 2 for explanation

\section{DISCUSSION}

We developed a modeling approach for predicting season-, size-, and sex-specific distribution of lobsters as a function of environmental and spatial variables. Validation tests of the model suggested reasonable predictive ability, and the results were consistent with the ecology of American lobster. The study provides a means to evaluate changes in lobster spatial distribu- tion with respect to environmental variables, which may be important for the management of American lobster in the face of shifting environmental conditions occurring with global climate change.

Environmental and spatial variables including salinity, temperature, depth, distance offshore, distance to sediment boundary, sediment type, latitude and longitude influenced the spatial distribution of American lobster. Although several covariates such as depth and

Table 2. Homarus americanus. Summary results of the regression analysis of the observed density on the predicted density for 2007. The coefficient estimates and adjusted $\mathrm{R}^{2}$ values are presented for each modeling group. Significant $\mathrm{p}$-values $(\mathrm{p}<0.05)$ in $\mathbf{b o l d}$

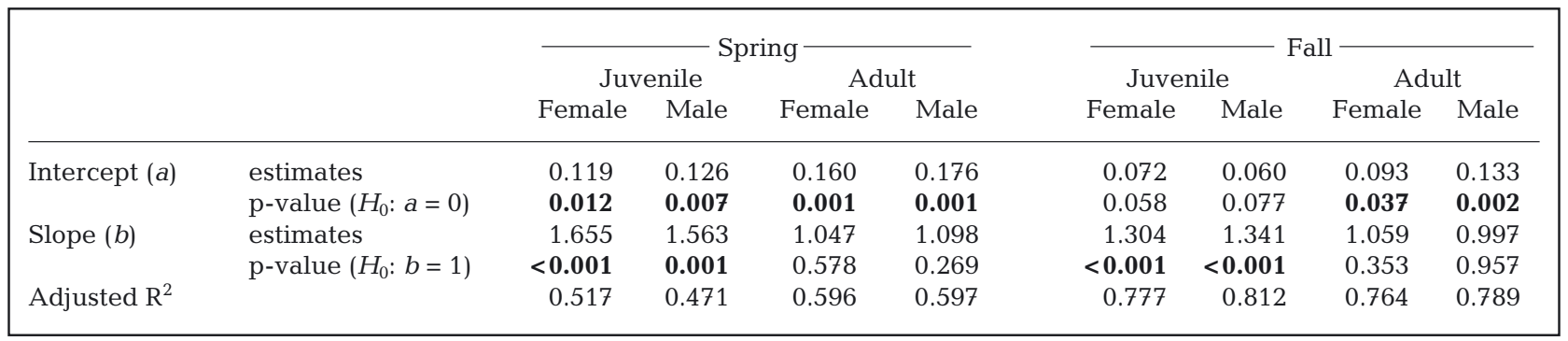




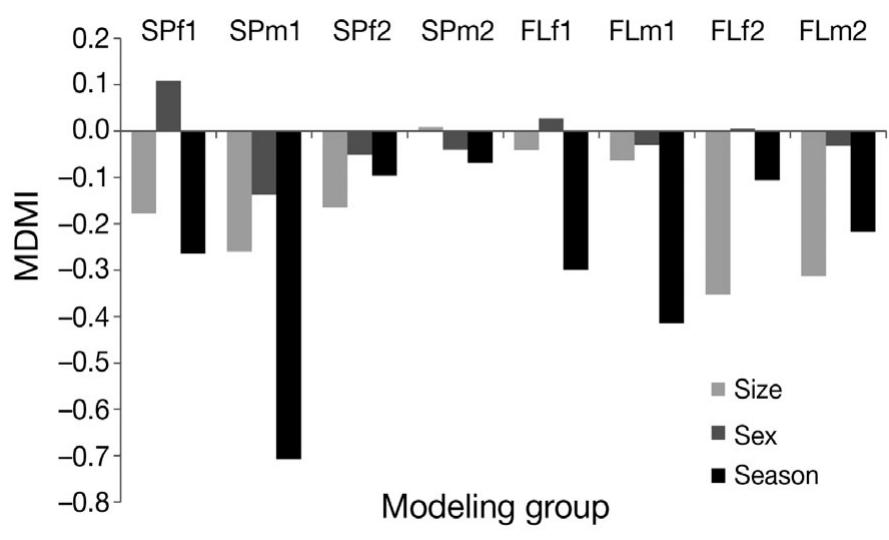

Fig. 5. Homarus americanus. Model-data mismatch impacts (MDMI) of sex, season, and size on the prediction of lobster densities. For abbreviations see Fig. 2 distance offshore were correlated, different combinations of attributes were important in predicting lobster distribution, and each covariate had a uniquely shaped response curve. Season-, sex-, and size-specific lobster responses to these covariates were found in both GAM1s and GAM2s, leading to distinct differences in spatial distributions for different groups.

Temperature was the most important environmental variable correlated with lobster density; as temperature increased, so did lobster density. Whereas higher water temperatures favor growth, since molting frequency increases with temperature (Aiken 1977), molt increment decreases with temperature (ASMFC 2009). Warmer water temperatures can cause maturation at smaller sizes (Aiken \& Waddy 1986, Little \& Watson 2003), but also oocyte resorption (Aiken \& Waddy 1986). Lobsters are reportedly able to sense changes in

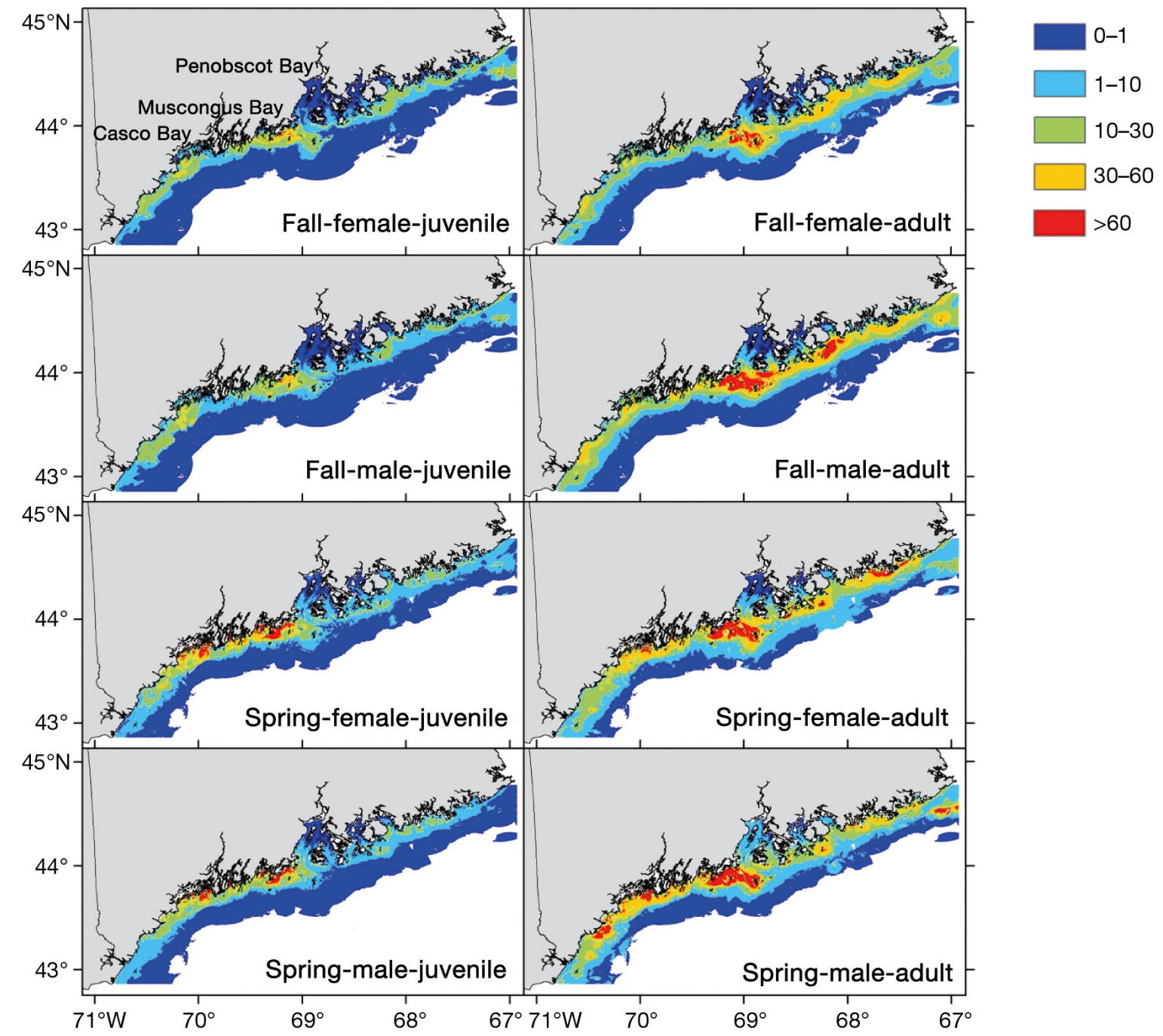

Fig. 6. Homarus americanus. Predicted season-, size-, and sex-specific lobster density (per $792 \mathrm{~m}^{2}$ ) distribution for 2006 


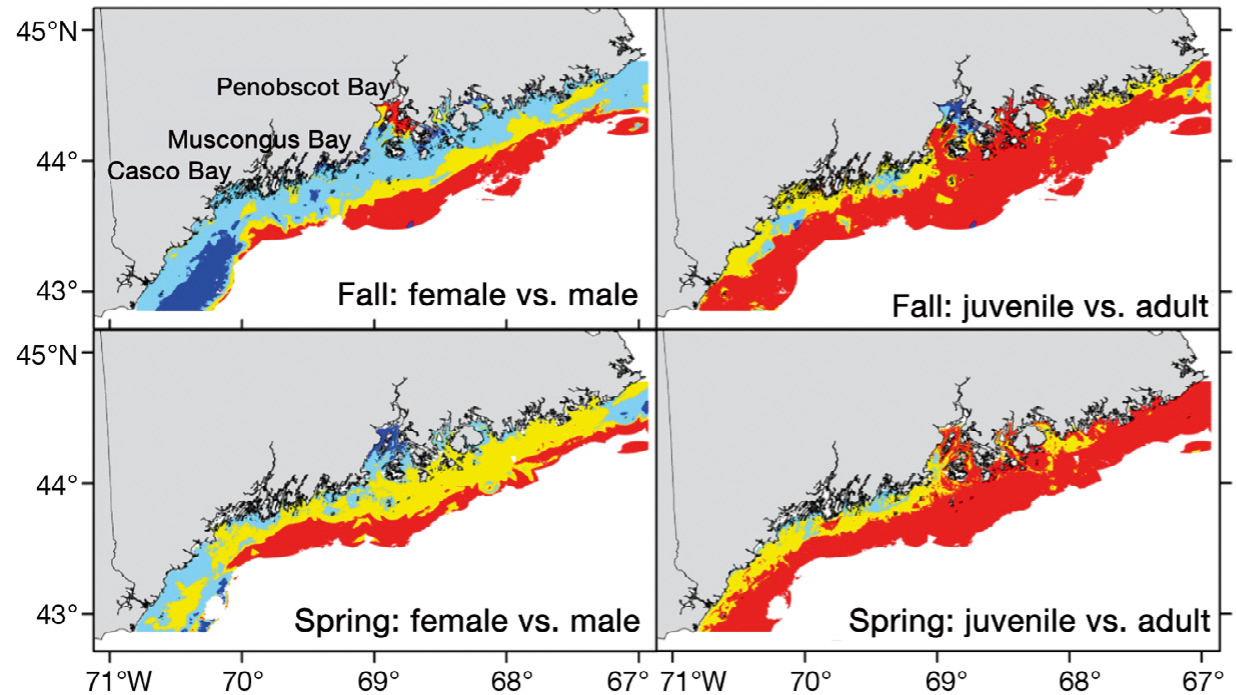

0-0.25 (Male/juvenile dominated)

$0.25-0.5$

$0.5-0.75$

$0.75-1$ (Female/adult dominated

Fig. 7. Homarus americanus. Ratios of female density to total density, and adult density to total density in spring and fall, 2006

water temperature and regulate their behavior accordingly (Crossin et al. 1998). Adult lobsters appear to follow isotherms and stay in relatively warm waters when water temperature does not exceed the thermal threshold (Ennis 1984). This is consistent with our predictions that adults concentrated in areas where water temperatures were greater than $5^{\circ} \mathrm{C}$ in spring and $8^{\circ} \mathrm{C}$ in fall, which were the common bottom water temperatures in the inshore waters along the entire coastal GOM.

Behavioral thermoregulation was more obvious for male than female adults as higher abundances of males occurred in warm inshore waters. Temperature strongly affects embryonic development and onset of hatching in American lobster (Aiken \& Waddy 1986). Migrations of ovigerous lobsters apparently maximize the degree-days of exposure for embryos (Lawton \& Lavalli 1995), although migratory (Cooper \& Uzmann 1971, Campbell 1986) and non-migratory (Cooper \& Uzmann 1980, Lawton \& Lavalli 1995) ovigerous lobsters have been detected in mark-recapture studies. Cowan et al. (2007) suggested that tagged ovigerous lobsters attempted to occupy water with consistent rather than high temperatures. Moreover, a low water temperature that is below $8^{\circ} \mathrm{C}$ or even $5^{\circ} \mathrm{C}$ may be required for ovarian development, which will affect the onset of the next brood (Waddy \& Aiken 1992). Adult females must balance the tradeoff between optimizing growth and promoting reproduction instead of simply residing in areas of high water temperatures to optimize growth. In our analyses, female adults were widely distributed along the coast rather than concentrated in warmer areas. Moreover, an adult-femaledominated sex ratio occurred in areas where bottom water temperatures were below $6^{\circ} \mathrm{C}$, although density was generally low in those areas.
In our analyses, lobster density increased with water temperature up to $14^{\circ} \mathrm{C}$. Where temperatures are above $19^{\circ} \mathrm{C}$, lobsters will avoid the habitats (Crossin et al. 1998) and a thermal threshold exists at $20.5^{\circ} \mathrm{C}$ (Powers et al. 2004). Such high water temperatures raise respiration rates or promote the release of harmful chemicals from sediments, both of which can be stressful or lethal for lobsters (Robohm \& Draxler 2003). Consequently, the relationship between lobster density and water temperature will be dome-shaped, with a peak somewhere between $14^{\circ} \mathrm{C}$ and $19^{\circ} \mathrm{C}$.

The American lobster has limited osmoregulatory capacity to adapt to variation in salinity (Jury et al. 1994). Extreme spring rainfall can lower bottom salinity dramatically and cause severe mortality (Thomas \& White 1969). Lobster tolerate salinities ranging between 15 and 32 (Harding 1992), and typically prefer higher salinities of 28 to 32 (Jury et al. 1994). Salinity had little effect on lobster density in our analysis, probably because most of our samples were at 30 to 34 , at which there is little variation in preference by American lobster (Jury et al. 1994). These results indicate that temperature is more important than salinity in driving the onshore-offshore lobster distribution in the GOM, such that lobster density is greater inshore where water temperature is higher.

Male lobsters are more abundant than females in the estuary (Munro \& Therriault 1983, Jury et al. 1994) because females are more sensitive to decreases in salinity (Jury et al. 1994). This is consistent with our prediction of the skewed sex ratio with males generally dominant in the coastal waters and females dominant in offshore waters. Although more males are predicted to reside along the coast, an adult-female-dominated sex ratio was predicted for Penobscot Bay estuary in 
the fall (Fig. 7). A similar difference was discovered in the study at Great Bay estuary (Jury et al. 1994), where it results from migrations of berried females into the estuary to hatch eggs. Estuarine habitats are characterized by large fluctuations in salinity, which can stress pelagic lobster larvae because they are sensitive to low salinities (Aiken \& Waddy 1986, Charmantier \& Aiken 1987). This might explain why berried females reside in the upper bay where salinity is relatively stable.

Lobsters in the early benthic phase (EBP), which ranges from 5 to $40 \mathrm{~mm} \mathrm{CL}$, are the most shelterrestricted of all stages in the life history (Wahle \& Steneck 1992). The EBP lobsters prefer shelter-providing substrates such as cobble (Wahle \& Steneck 1991), rocks on sand (Hudon 1987), and peat reefs (Able et al. 1988) because they provide refugia from predation and physical disturbance (Cobb et al. 1983, Wahle \& Steneck 1991). As juvenile lobsters grow out of EBP, the preference for specific substrates diminishes (Hudon 1987, Wahle \& Steneck 1991). This is consistent with our results where sediment type affected the probability of presences of juveniles but not adults. Similarly, the variable distance to sediment boundary, which was used to represent the complexity of the habitat, had a stronger effect on juveniles. Unlike for adults, which followed temperature and salinity gradients and were consequently abundant along the entire coast, our models predicted that juveniles should be dominant in inshore areas at lower latitudes where substrates are most complex in the GOM.

In spring, lobsters remain in the relatively warmer inshore waters (Ennis 1984, Jury et al. 1994, Watson et al. 1999), which promotes competition for limited shelter (Steneck 2006). Therefore, it is reasonable that lobsters were only affected by sediment type in spring when they were more concentrated in the warmer inshore waters.

Statistical modeling is a cost effective method to map species distributions in unsampled areas (Brotons et al. 2004), and consequently can be useful in predicting distributions. However, the models make a number of assumptions that can limit the applicability of the predictions. A major assumption of our models was that behavioral responses to environmental gradients did not vary between years. To test this assumption, we reestimated the models for each modeling group using the data from fall 2000 to fall 2005 (excluding the 2006 data), and used the 2007 data to validate the models. The 2007 data were still well predicted without 2006 data. The predictive power was similar but slightly better for the models using 2000 to 2006 data. Therefore, we conclude that the models constructed using historical data are somewhat robust to temporal change. However, if there are future substantial changes in ocean conditions that are outside the observed ranges, these models may not be suitable.

We used the coupled, but independently estimated, GAMs to estimate lobster presence and density in this study. An assumption behind this approach is that zero records indicate absence of lobster in the surveyed habitat rather than just low abundance. Variability of trawl survey estimates can be high for schooling fish species with highly patchy distributions, and zero records might occur when animals were present but missed by the trawl. However, lobsters do not form aggregations because they are solitary and territorial (Ennis 1984, Steneck \& Wilson 2001). Therefore, trawl survey densities are considered to be a reliable indicator of lobster presence, and have been used in indexing lobster abundance (Chen et al. 2006, ASMFC 2009). Moreover, Incze et al. (2010) examined lobster densities (>90 mm CL) from trawl surveys and visual lobster counts from remotely operated vehicle (ROV) surveys and concluded that, although ROV data were $~ 30 \%$ higher than trawl survey data, the difference was not statistically significant. Therefore, we believe that it is appropriate to use the coupled GAM in this study.

The value of GAM1 was evaluated by using only GAM2 to predict the 2007 data, which decreased $\mathrm{R}^{2}$ values for all groups. We also re-estimated the models using a single GAM with a quasi-Poisson error distribution, which performed slightly better for some juvenile groups but worse for all adult groups. To maintain consistency and retain both presence/absence and density predictions, we believe the coupled GAM used in this study is preferable.

Our study utilized trawl survey data, which might not reflect true lobster density. High lobster densities occur in habitats with boulder (Cooper \& Uzmann 1980) and rocky substrates (Steneck 2006). However, those habitats generally have poor trawl capture efficiency (Steneck \& Wilson 2001), and are not sampled by the Maine DMR trawl survey. Our data showed that the highest mean lobster captures were in the claysilt/sand areas followed by gravel area, but our sediment maps (Poppe et al. 2005) did not categorize the boulder substrate. Moreover, we cannot quantify the effect of the absence of survey data from boulder and cobble habitats on our results. The lack of trawl surveys from certain habitats likely resulted in the model underestimating the importance of the sedimentrelated variables, and might affect the explanatory power of the model. Although we cannot ignore this weakness of trawl survey data, the hot spots (e.g. western coastal areas of Penobscot Bay) and cold spots (e.g. northeast corner of Penobscot Bay) predicted by our models coincide with those from quadrat surveys (Steneck \& Wilson 2001), suggesting that our models are robust to trawl survey bias. 
Acknowledgements. We thank K. Stepanek, S. Sherman and C. Wilson of Maine Department of Marine Resources for providing the trawl survey information ${ }_{r i}$ A. Thomas, H. Xue, R. Wahle and J. Wilson for valuable comments and discussion; and D. Brzezinski for editing the MS. We thank the detailed and constructive comments from Editor R. Lipcius and the 4 anonymous reviewers. Financial support for this study was provided partially by the NSF Award no. 0709527 and NASA Grant no. NNX08AT92G.

\section{LITERATURE CITED}

Able KW, Heck KL, Fahay MP, Roman CT (1988) Use of saltmarsh peat reefs by small juvenile lobsters on Cape Cod, Massachusetts. Estuaries 11:83-86

Aiken DE (1977) Molting and growth in decapod crustaceans with particular reference to the lobster (Homarus americanus). CSIRO Div Fish Oceanogr Circ 7:41-73

Aiken DE, Waddy SL (1986) Environmental influence on recruitment of the American lobster, Homarus americanus: a perspective. Can J Fish Aquat Sci 43:2258-2270

ASMFC (Atlantic States Marine Fisheries Commission) (2009) American lobster stock assessment report for peer review. ASMFC, Arlington, VA

Austin M (2007) Species distribution models and ecological theory: a critical assessment and some possible new approaches. Ecol Model 200:1-19

Backus RH (1987) Georges Bank. MIT Press, Cambridge, MA

- Barry SC, Welsh AH (2002) Generalized additive modeling and zero inflated count data. Ecol Model 157:179-188

Briggs PT (1985) Movement of the American lobster off the south shore of Long Island, New York. New York Fish Game 32:20-25

Brotons L, Thuiller W, Araújo MB, Hirzel AH (2004) Presenceabsence versus presence-only modelling methods for predicting bird habitat suitability. Ecography 27:437-448

Campbell A (1986) Migratory movements of ovigerous lobsters, Homarus americanus, tagged off Grand Manan, eastern Canada. Can J Fish Aquat Sci 43:2197-2205

- Campbell A (1990) Aggregations of berried lobsters (Homarus americanus) in shallow waters off Grand Manan, eastern Canada. Can J Fish Aquat Sci 47:520-523

Charmantier G, Aiken DE (1987) Osmotic regulation in late embryos and prelarvae of the American lobster Homarus americanus H. Milne-Edwards, 1837 (Crustacea, Decapoda). J Exp Mar Biol Ecol 109:101-108

Chen Y, Sherman S, Wilson C, Sowles J, Kanaiwa M (2006) A comparison of two fishery-independent survey programs used to define the population structure of American lobster (Homarus americanus) in the Gulf of Maine. Fish Bull 104:247-255

Cobb JS, Gulbranson T, Phillips BF, Wang D, Syslo M (1983) Behavior and distribution of larval and early juvenile Honiarus americanus. Can J Fish Aquat Sci 40:2184-2188

Cooper RA, Uzmann JR (1971) Migrations and growth of deep-sea lobsters, Homarus americanus. Science 171: 288-290

Cooper RA, Uzmann JR (1980) Ecology of juvenile and adult Homarua. In: Cobb JS, Phillips R (eds) The biology and management of lobsters, Vol. 2. Academic Press, New York, NY, p 97-141

> Cooper RA, Clifford RA, Newell CD (1975) Seasonal abundance of the American lobster, Homarus americanus, in the Boothbay Region of Maine. Trans Am Fish Soc 104: 669-674

Cowan DF, Watson W, Solow A, Mountcastle A (2007) Ther- mal histories of brooding lobsters, Homarus americanus, in the Gulf of Maine. Mar Biol 150:463-470

Crossin G, Al-Ayoub S, Jury S, Howell WH, Watson W III (1998) Behavioral thermoregulation in the American lobster Homarus americanus. J Exp Biol 201:365-374

Eastwood PD, Meaden GJ, Grioche A (2001) Modeling spatial variations in spawning habitat suitability for the sole, Solea solea, using regression quantiles and GIS procedures. Mar Ecol Prog Ser 224:251-266

Ennis GP (1984) Small scale seasonal movements of the American lobster Homarus americanus. Trans Am Fish Soc 113:336-338

Factor JR (1995) Biology of the lobster, Homarus americanus. Academic Press, San Diego, CA

Grosslein MD, Azarovitz TR (1982) Fish distribution: MESA New York Bight Atlas Monograph 15. Sea Grant Institute, NY

Guisan A, Edwards TC, Hastie T (2002) Generalized linear and generalized additive models in studies of species distributions: setting the scene. Ecol Model 157:89-100

Harding GC (1992) American lobster, Homarus americanus: a discussion paper on their environmental requirements and the known anthropogenic effects on their populations. Can Tech Rep Fish Aquat Sci No. 1887

Hastie TJ, Tibshirani RJ (1990) Generalized additive models. Chapman \& Hall, London

Hudon C (1987) Ecology and growth of post-larval and juvenile lobster, Homarus americanus, off Iles de la Madeleine (Quebec). Can J Fish Aquat Sci 44:1855-1869

Incze LS, Wahle RA, Wolff N, Wilson C and others (2006) Early life history of lobster (Homarus americanus) populations in the Gulf of Maine. J Crustac Biol 26:555-564

Incze L, Xue H, Wolff N, Xu D and others (2010) Connectivity of lobster (Homarus americanus) populations in the coastal Gulf of Maine: part II. Coupled biophysical dynamics. Fish Oceanogr 19:1-20

> Jensen OP, Seppelt R, Miller TJ, Bauer LJ (2005) Winter distribution of blue crab Callinectes sapidus in Chesapeake Bay: application and cross-validation of a two-stage generalized additive model. Mar Ecol Prog Ser 299:239-255

> Jury SH, Kinnison MT, Howell WH, Watson WH (1994) The behavior of lobsters in response to reduced salinity. J Exp Mar Biol Ecol 180:23-27

Karnofsky EB, Atema J, Elgin RH (1989) Natural dynamics of population structure and habitat use of the lobster, Homarus americanus, in a shallow cove. Biol Bull (Woods Hole) 176: 247-256

Kupschus S (2003) Development and evaluation of statistical habitat suitability models: an example based on juvenile spotted seatrout Cynoscion nebulosus. Mar Ecol Prog Ser 265:197-212

Lawton P, Lavalli KL (1995) Postlarval, juvenile, adolescent and adult ecology. In: Factor JR (Ed) Biology of the lobster: Homarus americanus. Academic Press, San Diego, CA, p 47-88

Lehmann A, Overton JM, Leathwick JR (2002) GRASP: generalized regression analysis and spatial prediction. Ecol Model 157:189-207

Little S, Watson W III (2003) Size at maturity of female lobster from an estuarine and coastal population. J Shellfish Res 22:857-863

- Maunder MN, Punt AE (2004) Standardizing catch and effort data: a review of recent approaches. Fish Res 70:141-159

- Munro J, Therriault JC (1983) Migrations saisonnières du homard (Homarus americanus) entre la côte et les lagunes des Iles de la Madeleine. Can J Fish Aquat Sci 40:905-918

Palma AT, Steneck RS, Wilson J (1999) Settlement-driven, 
multiscale demographic patterns of large benthic decapods in the Gulf of Maine. J Exp Mar Biol Ecol 241: 107-136

Poppe LJ, Williams SJ, Paskevich VF (2005) USGS east-coast sediment analysis: procedures, database, and GIS data. US Geological Survey open-file report 2005-1001. Available at: http://purl.access.gpo.gov/GPO/LPS105723

Powers J, Lopez G, Cerrato R, Dove A (2004) Effects of thermal stress on Long Island Sound lobster, H. americanus. Proc Long Island Sound Lobster Research Initiative Working Meeting, University of Connecticut at Avery Point, Groton, CT

Pringle JP, Burke DL (1993) The Canadian lobster fishery and its management, with emphasis on the Scotian Shelf and Gulf of Maine. Can Bull Fish Aquat Sci 226:91-122

Ray N, Lehmann A, Joly P (2002) Modelling spatial distribution of amphibian populations: a GIS approach based on habitat matrix permeability. Biodivers Conserv 11: 2143-2165

Robohm R, Draxler A (2003) Effects of environmental stressors on disease susceptibility in lobster: a controlled laboratory study. Proc Long Island Sound Lobster Research Initiative Working Meeting, University of Connecticut at Avery Point, Groton, CT.

Roworth E, Signell R (1998) Construction of digital bathymetry for the Gulf of Maine: US Geological Survey Open-File Report 98-801. Available at: http://pubs.usgs.gov/of/1998/ of98-801/

Steneck RS (2006) Possible demographic consequences of intraspecific shelter competition among American lobster. J Crustac Biol 26:628-638

Editorial responsibility: Romuald Lipcius, Gloucester Point, Virginia, USA
Steneck RS, Wilson CJ (2001) Large-scale and long-term, spatial and temporal patterns in demography and landings of the American lobster, Homarus americanus, in Maine. Mar Freshw Res 52:1303-1319

Thomas MLH, White GN (1969) Mass mortality of estuarine fauna at Bideford, P.E.I., associated with abnormally low salinities. J Fish Res Bd Can 26:701-704

Waddy S, Aiken DE (1992) Environmental intervention in the reproductive process of the American lobster, Homarus americanus. Invertebr Reprod Dev 22:245-252

> Wahle RA, Steneck RS (1991) Recruitment habitats and nursery grounds of the American lobster, Homarus americanus: a demographic bottleneck? Mar Ecol Prog Ser 69: 231-243

Wahle RA, Steneck RS (1992) Habitat restrictions in early benthic life: experiments on habitat selection and in situ predation with the American lobster. J Exp Mar Biol Ecol 157:91-114

Watson WH III, Vetrovs A, Howell WH (1999) Lobster movements in an estuary. Mar Biol 134:65-75

Wilson CJ (1998) Bathymetric and spatial patterns of settlement in American lobsters, $H$. americanus, in the Gulf of Maine: Insights into processes controlling abundance. MS thesis, University of Maine, Orono, NE

$>$ Xue H, Shi L, Cousins S, Pettigrew NR (2005) The GoMOOS nowcast/forecast system. Cont Shelf Res 25:2122-2146

> Xue H, Incze L, Xu D, Wolff N, Pettigrew N (2008) Connectivity of lobster populations in the coastal Gulf of Maine. Part I: Circulation and larval transport potential. Ecol Model 210:193-211

Submitted: October 26, 2010; Accepted: September 27, 2010 Proofs received from author(s): November 30, 2010 